\title{
Animal Models of Cancer Stem Cells: What are They Really Telling Us?
}

\author{
Christopher Aiken - Tamra Werbowetski-Ogilvie
}

Published online: 9 March 2013

(c) Springer Science+Business Media New York 2013

\begin{abstract}
The cancer stem cell hypothesis suggests that a subpopulation of tumor cells exhibits stem cell properties such as self-renewal capacity and multilineage differentiation. The modern day cancer stem cell model emerged following initial work in leukemia and subsequent identification of putative cancer stem cell populations in a variety of solid tumors. These studies have been largely based on transplantation assays in immunodeficient mice and have revolutionized how we view tumor cell heterogeneity. However, recent studies with both genetically engineered and more highly immunocompromised animal models have challenged the notion that cancer stem cells are a rare subpopulation. Issues with the cell surface markers used to enrich for cancer stem cells and the hierarchical organization within tumors have also come to light and remain unresolved. As we continue to optimize in vivo models and understand microenvironmental influences, our view of cancer stem cells within heterogeneous tumors will likely become even more complex.
\end{abstract}

Keywords Cancer stem cell - CSC - Tumor propagating cell $\cdot$ NOD/SCID $\cdot$ Xenograft · Genetically engineered mice $\cdot$ GEM $\cdot$ Pathobiology

C. Aiken - T. Werbowetski-Ogilvie

Regenerative Medicine Program, Department of Physiology, University of Manitoba, 600-745 Bannatyne Avenue,

Winnipeg, MB R3E 0J9, Canada

e-mail: umaiken@cc.umanitoba.ca

T. Werbowetski-Ogilvie ( $\square)$

Regenerative Medicine Program, Department of Biochemistry

and Medical Genetics, University of Manitoba, 611-745

Bannatyne Avenue, Winnipeg, MB R3E 0J9, Canada

e-mail:ogilviet@cc.umanitoba.ca

\section{Introduction}

Current cancer stem cell (CSC) theory posits that tumors contain cell subpopulations that exhibit stem cell features such as self-renewal capacity and multilineage differentiation [1-3]. These CSCs or tumor-propagating cells (TPCs) would ultimately drive tumorigenesis and must, therefore, be specifically targeted to abrogate malignant progression. While the idea of a CSC dates back several decades (See Dick [4] for a comprehensive historical overview of CSC theory), the modern day CSC model emerged following extensive studies in leukemia demonstrating that only a rare cell population could initiate tumorigenesis when transplanted into immunodeficient mice [5, 6]. This tumorinitiating capacity could be enriched by cell sorting based on CD34+/CD38 - cell surface marker expression [5, 6]. Following the initial work in acute myelogenous leukemia (AML), a large number of studies have since been published on CSCs or TPCs in solid tumors including breast [7], brain [8, 9], colon [10, 11], pancreatic [12] and ovarian cancers [13-16]. Similar to the work with hematopoietic malignancies, these studies also utilized non-obese diabetic severe combined immunodeficient (NOD/SCID) mice to demonstrate that the tumor-initiating capacity was restricted to a rare cell subpopulation defined by specific cell surface markers.

Since these initial seminal studies were published, the CSC model has generated a lot of controversy with regards to the cell of origin, frequency of tumor initiating cells and the markers used to enrich for putative CSC subpopulations. For example, using genetically engineered mouse (GEM) models and thus immunocompetent systems, some research groups have demonstrated that transplanting as few as 10 cells is sufficient to generate a tumor in wildtype recipient mice [17••]. In these mouse models of B cell and 
T cell lymphoma and AML, tumor initiation does not seem to be driven by rare CSC subpopulations. Moreover, recent studies using even more immunocompromised animal models such as NOD/SCID mice lacking the interleukin-2 gamma receptor (NOD/SCID IL2R $\gamma^{\text {null }}$ ) demonstrated that changes in tumor microenvironment can result in a drastic increase in the number of cells capable of forming a tumor [18••]. These results underscore the potential for some xenotransplantation assays to underestimate the number of cells with CSC or tumor-initiating cell capacity.

To date, the discrepancies between different in vivo models of CSCs have yet to be resolved. This review will specifically focus on the last 5 years of CSC research, with an emphasis on the landmark animal model studies that raised further questions regarding the status of CSCs in both hematopoietic malignancies and solid tumors. Comparative results in xenograft and GEM (transgenic and knockout) animal models will be discussed. Each model will be evaluated in terms of putative CSC frequency, cell surface phenotyping and correlation with in vitro stem cell assays, as well as hierarchical arrangement of cell populations within tumors. Emerging alternative systems such xenograft zebrafish models are also examined.

\section{Xenotransplantation Assays, GEM Models and the Frequency Issue}

Xenotransplantation into immunodeficient mice has become the gold standard for evaluation of CSC properties from human tumors in vivo. Researchers have used this assay to determine the tumor initiating capacity of both unsorted and sorted fractions of human cells based on specific combinations of cell surface markers in a variety of cancers. Dissociation of primary tumors and transplantation into secondary mouse recipients enables one to evaluate self-renewal in vivo. Combined with data from limiting dilution analysis, the results for primary and secondary tumors are used to calculate a tumor-initiating cell frequency using a maximum-likelihood estimation method $[19,20]$. This will determine whether a small or large subset of cells from different cancers can initiate tumor growth.

While utilization of this assay to define CSCs has led to seminal findings in cancer research, it should be emphasized that human cells in a mouse microenvironment differ from those cancer cells that grow and thrive in patients. Mouse and human tissues exhibit differences between their normal tissue stroma [21]. It is well known that the normal cell microenvironment, consisting of stromal fibroblasts, vascular networks, extracellular matrix and autologous immune cells, plays an important role in regulating tumorigenesis [22]. This includes both positive and negative effects on tumor growth and maintenance [22]. There are obviously vast differences in the immune cell function between autologous and xenogeneic systems. Case in point, transplantation of human cells into even more immunodeficient mouse models has yielded very different results from those studies utilizing NOD/SCID mice. Quintana et al. [18••] demonstrated that transplantation of melanoma cells into the highly immunocompromised NOD/SCID IL2R $\gamma^{\text {null }}$ mice led to an increase in the detection of tumorigenic cells by several orders of magnitude. NOD/SCID IL2R $\gamma^{\text {null }}$ mice lack natural-killer cell activity relative to NOD/SCID mice and therefore provide an even more permissive environment for successful engraftment of human cells. In fact, compared to the tumor-initiating capacity of 1 in 1,090,000 in NOD/SCID mice [23], xenotransplantation assays in NOD/SCID IL $2 \mathrm{R} \gamma^{\text {null }}$ mice resulted in an average of one in nine melanoma cells forming tumors [18••]. These results indicate that modified in vivo assay conditions can dramatically change the CSC output, and that in some cases, tumors that appeared to have a rare subpopulation of tumor initiating cells or CSCs were actually maintained by a large number of cells with tumorigenic capacity.

While rarity is not a prerequisite for tumor-initiating capacity in melanoma, for other cancers such as AML, transplantation of human cells in multiple mouse models still supports the CSC hierarchical model and the maintenance by a relatively less frequent subpopulation of tumor cells [24]. For example, detection of long-term engrafting and selfrenewing leukemic stem cells was demonstrated with transplantation of as few as $10^{3}$ highly purified CD34+/ CD38-human AML cells into NOD/SCID IL2R $\gamma^{\text {null }}$ mice [25]. Even with this improved, more permissive xenograft assay, CSC populations in AML still appear to be relatively rare. Kennedy et al. [24] reported similar findings using a model of human B cell acute lymphoblastic leukemia (B-ALL). The frequency of leukemic stem cells in these tumors was approximately $1 \%$ [24], and increased by orders of magnitude above previously reported results [18••]. Most recently, Eppert et al. [26•] used stem cell gene expression signatures from functionally validated sorted primary human AML fractions to predict poor patient prognosis. These studies underscore the clinical relevance of CSC populations and suggest that these cellular phenotypes are not merely an artifact of xenotransplantation [26•].

As the use of more immunodeficient NOD/SCID IL2R $\gamma^{\text {null }}$ mice gained momentum, researchers began to conduct side by side experiments with other mouse models. Most recently, Ishizawa et al. [27] directly compared the growth of human pancreatic, head and neck carcinomas and lung cancers in NOD/SCID and NOD/SCID IL2R $\gamma^{\text {null }}$ mice. Despite an up to ten-fold increase in the detection of tumorigenic cells in NOD/SCID IL2R $\gamma^{\text {null }}$ mice and extensive variability within 
tumors, the frequency remained relatively low at $<1: 2,500$ cells for all tumors investigated [27]. However, there were notable differences between the malignancies studied. For example, the frequency of CSCs in pancreatic and head and neck cancer did not significantly differ between NOD/SCID and NOD/SCID IL2R $\gamma^{\text {null }}$ mice [27]. In contrast, there was a statistical increase in the readout for all cases of squamous cell lung carcinoma when tumor cells were injected into NOD/SCID IL2R $\gamma^{\text {null }}$ mice [27]. Similar results were obtained for comparative studies in high-grade serous ovarian cancer where the frequency of CSCs was significantly higher in four of ten cases when injected into NOD/SCID IL2R $\gamma^{\text {null }}$ mice [15]. As the more permissive NOD/SCID IL2R $\gamma^{\text {null }}$ microenvironment did not alter the functional characteristics of pancreatic and head and neck CSCs, perhaps these malignancies more closely adhere to the CSC model.

As putative human CSCs must be transplanted into immunocompromised mice to effectively assay tumor initiation in vivo, this has led to questions regarding the relevance of certain models in recapitulating human disease. Perhaps one of the most contentious issues among scientists studying CSCs is the frequency of this subpopulation within a tumor. Researchers have reported a wide variation in the percentage of cells that can initiate tumorigenesis using xenograft models [3]. For cancers such as melanoma, animal models like NOD/SCID mice vastly underestimate the frequency of tumorigenic cells $[18 \bullet \bullet]$. However, it should be noted that rarity is not an obligatory feature of CSC populations. A higher cell frequency does not exclude a subpopulation from following a CSC hierarchical model. It has been suggested that these common tumorigenic cells may be part of a more "shallow" or limited hierarchy [3]. However, cancers such as malignant peripheral nerve sheath tumors, exhibiting a higher frequency of tumorigenic cells, have yet to be hierarchically evaluated [28]. Interestingly, melanoma has also been one of the few cancers to be reprogrammed by nuclear transfer [29] as well as by ectopic expression of Oct4, Klf4 and c-myc to the induced pluripotent stem (iPS) cell state [30]. Perhaps the incredible plasticity and adaptability of melanoma cells in various microenvironments suggests that these tumor cells may be the exception and not the rule in CSC biology.

While serial xenotransplantations assays and limiting dilution analysis are traditionally the gold standard for in vivo assessment of putative human CSC populations, these models have been plagued by a series of technical issues. Murine microenvironments and inappropriate immune responses combined with variations seen with transplantation site, recipient mouse sex and strain have prompted scientists to move towards studying CSC properties in immunocompetent, GEM models.

Kelly et al. [17•0] were the first to challenge the notion that CSCs are a rare subpopulation by reporting that tumorigenic cells were more common in certain mouse models of lymphoma (both B cell and T cell) as well as a PU.1 deficient model of AML. Transplantation with as few as ten cells resulted in tumor development [17••]. Similar trends were also observed using a mouse model of B-ALL [31].

For solid tumors, higher frequencies of CSCs or tumorigenic cells have been reported in mouse models of melanoma [32], peripheral nerve sheath tumors [28], breast [33] and brain [34, 35]. Buchstaller et al. [28] reported a range of tumorigenic cell frequencies using multiple mouse models of peripheral nerve sheath tumors. Frequency was dependent on both the genotype of the mouse model utilized and the specific assay conditions used to report tumor-initiating capacity [28]. Similarly, Tamase et al. [34] demonstrated that the tumorigenic cell population varied from about $16-50 \%$ in individual brain tumors derived from a Ras induced p16Ink4a/p19Arf-deficient mouse model of glioblastoma combined with a GFP reporting system. However, in this model system, the authors did not distinguish between stem cells and progenitors suggesting that either or both cell types could contribute to the tumorinitiating capacity [34]. Collectively, these studies using GEM models have underscored the notion that tumors do not have to be driven by a rare CSC phenotype. In many instances, the tumorigenic cell frequency is upwards of $50 \%$ or more. As rarity is not a prerequisite defining feature of CSCs, it is becoming increasingly acceptable for a more common cell population to be considered a CSC, tumor initiating or propagating cell.

\section{Xenografts, GEMs and "Markerology"}

In addition to the CSC frequency disparities between xenograft models and GEMs, researchers have also seen differences in the cell surface markers used to identify and isolate CSC fractions in these model systems. Some of the best examples of these discrepancies are in breast and brain tumor models and are summarized in Table 1. For example, using serial xenotransplantation assays in the mammary fat pad, Al-Hajj et al. [7] were the first to isolate CSCs from human breast cancers. This study, which was the first characterization of CSCs in solid tumors, isolated breast tumor stem cells based on combinatory CD44+/ CD24 ${ }^{\text {low }}$ expression [7].

In contrast, murine models of breast cancer have used different cell surface markers to isolate mammary tumor stem cells [33, 36-39]. Using a p53-null mammary tumor model, Zhang et al. [37] showed that a subpopulation of CD24+/CD29+ cells exhibit self-renewal capacity in subsequent transplantation assays and recapitulate phenotypic properties of the primary tumor. Interestingly, a 
Table 1 Differences in markers used to select for CSC populations in xenograft versus genetically engineered murine models of breast and brain cancer

\begin{tabular}{|c|c|c|c|c|}
\hline \multirow[t]{2}{*}{ Tumor Type } & \multicolumn{2}{|l|}{ Xenograft } & \multicolumn{2}{|l|}{ GEM } \\
\hline & Markers & References & Markers & References \\
\hline Breast & $\mathrm{CD} 44+/ \mathrm{CD} 24^{\text {low }}$ & Al-Hajj et al. [7] & $\begin{array}{l}\text { Lin-/CD24+/CD29+ } \\
\text { Thy } 1+/ C D 24+ \\
\text { CD29 }{ }^{\text {low }} / \mathrm{CD} 24+/ \mathrm{CD} 61+ \\
\text { Sca- } 1+ \\
\mathrm{CD} 24^{+} \mathrm{CD} 29^{+} \mathrm{CD} 49 \mathrm{f}^{+} \mathrm{Sca}-1^{\text {low }}\end{array}$ & $\begin{array}{l}\text { Zhang et al. [37] } \\
\text { Cho et al. [36] } \\
\text { Vaillant et al. [33] } \\
\text { Grange et al. [39] } \\
\text { Ma et al. [38] }\end{array}$ \\
\hline Brain & CD133+ & Singh et al. $[8,9]$ & $\begin{array}{l}\text { Math1+ and CD15+ } \\
\text { CD15+ } \\
\text { ID } 1^{\text {high }} \text { (in vitro) and ID1 }{ }^{\text {low }} \text { (higher } \\
\text { tumorigenic potential in vivo) }\end{array}$ & $\begin{array}{l}\text { Read et al. [50] } \\
\text { Ward et al. [51] } \\
\text { Barrett et al. [55] }\end{array}$ \\
\hline
\end{tabular}

Thy1+/CD24+ cell population displayed CSC properties in a MMTV-Wnt1 mouse breast cancer model [36], while Vaillant et al. [33] demonstrated that CD29 ${ }^{\text {low }} / \mathrm{CD} 24+/$ CD61+ selectivity enriched for highly tumorigenic stem cells in this same system. For breast cancer, there are clear discrepancies between the markers used to identify CSC populations in xenograft models and GEMs. In addition, the hierarchical organization within mammary tumors is still not well defined, and together, these issues make it difficult to assess which markers can be relied upon to reproducibly select for breast CSCs.

A similar issue with cell surface markers has been documented in malignant brain tumors. While CD133 has typically been utilized as a putative human brain tumor stem cell marker [8, 9] recent work has shown that CD133 - cells display more invasive growth and aggressive behaviour than the CD133+ cells typically associated with "stem cell" function [40, 41]. Chen et al. [41] demonstrated that a more primitive CD133 - subpopulation of GBM cells gives rise to both CD133 - and CD133+ subsets. This was not restricted to a single tumor subtype as CD133 - cells from both colon cancer [42] and brain tumors [40, 42-44] developed metastatic and highly invasive tumors respectively. This is complicated by the fact that CD133 is not exclusive to TPC populations and is also expressed in normal stem cells as well as differentiated epithelial cells in a variety of organs [45]. In fact, very little is actually known about the biological function of CD133. From a technical standpoint, antibodies currently used to isolate CSC populations recognize glycosylated epitopes that have not been fully characterized, and it has yet to be determined whether the CD133 protein or its glycosylation status is correlated with the CSC phenotype (See Bidlingmaier et al. [46] for a comprehensive overview of controversies regarding utilization of CD133 glycosylated human epitopes in defining CSCs). Interestingly, recent studies have also demonstrated that glycosylated CD133 levels are enhanced by lowering oxygen tension from 20 to 2-3\% demonstrating that CD133 function and hypoxia are linked [47-49]. While there are still several issues to be resolved, it will be necessary to break down the heterogeneity within CD133 \pm populations to identify other markers that better select for self-renewing and possibly the most aggressive, highly invasive phenotypes.

CD133 has been used for isolation of human brain CSCs; however, in mouse models, recent studies have shown that CD15 or stage-specific embryonic antigen (SSEA1) selects for a tumorigenic cell population [50, 51]. For example, Read et al. [50] demonstrated that in a Ptc \pm model of medulloblastoma, the most common malignant primary pediatric brain tumor, tumors are propagated not by a stem cell-like CD133+ (Prominin-1 in mice) population but by cells marked by the neuronal progenitor markers Math1 and CD15. Interestingly, CD133 + cells from Ptc \pm mice did not form tumorspheres in vitro and were not capable of forming tumors when transplanted into the cerebellum of SCID-beige mice [50]. Ward et al. [51] also demonstrated the tumorigenic capacity of CD15+ cells from Ptc \pm mice; however, these authors suggested that the CD15+ population represents a stem cell-like and not a progenitor cell phenotype. Additional studies have lent further support to the notion that in some murine brain tumor models, including medulloblastoma [52] [53], and oligodendroglioma [54], the cell of origin is a more restricted progenitor and not a stem cell.

Controversies surrounding brain tumor stem cell properties were further emphasized with the recent uncoupling of self-renewal in vitro from tumorigenic capacity in vivo. Using PDGF and KRAS-driven models of glioma, Barrett et al. [55] recently showed that cell populations sorted on the Inhibitor of DNA binding (ID1) protein exhibit a higher self-renewal capacity in vitro; however, these same cells demonstrate a lower tumorigenic capacity in vivo. While both ID $1^{\text {high }}$ and ID $1^{\text {low }}$ cells were tumorigenic in transplantation assays, these results clearly demonstrate that 
multiple lineages, including those with limited self-renewal capacity, are capable of transplanting disease [55]. Further studies that evaluate the correlation between in vivo tumorigenicity or in vitro self-renewal with patient prognosis and survival will ultimately determine which assay has greater relevance to clinical outcome.

Collectively, the differences seen between xenotransplantation assays and GEMs have several clinical implications. For example, many laboratories are working with high throughput screening technologies to identify chemical compounds that will selectively target a putative CSC or tumorigenic cell population, irrespective of whether these cells take on a more stem cell-like or progenitor phenotype. However, for these expensive screens to be valid and more importantly useful from a clinical perspective, we must be able to reproducibly select for these cell populations based on combinatory cell surface marker expression. When there are vast differences between xenograft assays and mouse models, this begs the question: What is the most reliable system for accurate prospective isolation of putative CSCs or tumor-initiating cells? While xenografts often use human cells directly isolated from patient samples, GEM technology has developed tremendously over the years, and many mouse models do recapitulate the phenotypes of their human counterparts. Ultimately, the most convincing new therapeutic targets and relevant clinical data will come from compounds that can selectively target these populations in both a xenograft and mouse model.

\section{Xenografts, GEMs and Hierarchical Organization}

While many CSC studies with GEM models have focused on the frequency controversy, more recent studies have utilized these models to address the concept of cellular hierarchies. To adhere to the CSC model, a cell population must exhibit two properties: (1) phenotypic and functional heterogeneity and (2) hierarchical organization [3]. Cellular hierarchies are defined by the tumorigenic stem cell's ability to give rise to both tumorigenic as well as nontumorigenic cells following transplantation. Using a Nf1/ p53/Pten malignant glioma mouse model combined with a nestin- $\Delta$ TK-IRES-GFP transgene, Chen et al. [56] recently reported that a subset of endogenous CSCs are the source of new tumor growth following ablation of proliferating cells with temozolomide. Combined treatment with ganciclovir significantly abrogated tumor progression through selective targeting of the GFP+ CSC-like population. In this glioma model, tumors follow a hierarchical CSC system, and recurrence is specifically attributed to failed eradication of the CSC subpopulation [56]. This study reaffirmed the clinical relevance of putative CSCs in malignant glioblastoma.
Perhaps the most consistent and convincing evidence for a CSC hierarchical model has come from the collective studies on AML [4]. However, even within this tumor, recent studies have demonstrated variability and added to the increasing complexity of the CSC model. In NOD/ SCID mice, rare leukemic stem cells were originally shown to be exclusive to the CD34+/CD38 - fraction, and only this population generated tumors in subsequent transplantation studies [5, 6]. CSC studies on AML have become the standard from which all other CSC studies are measured. However, recent utilization of more immunodeficient models such as NOD/SCID IL2R $\gamma^{\text {null }}$ mice has led to the finding that the tumorigenic subpopulation is not exclusive

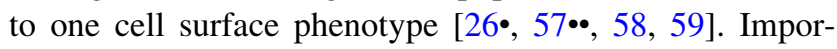
tantly, Taussig et al. [57••] have shown that CD38 antibodies can have a tremendous influence on engraftment of leukemic cells, and when this inhibitory effect is overcome, the CD34+/CD38+ fraction was revealed to contain substantial tumor-initiating cell capacity. Furthermore, Eppert and colleagues have shown that the tumorigenic capacity is not restricted to the CD34+/CD38- subpopulation in

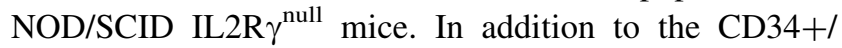
CD38+ cells, CD34- cells possessed leukemic stem cells, albeit to a lesser extent [26•]. These studies suggest a plasticity of the CSC phenotype and demonstrate that the hierarchy for various tumors, including AML, is not as well defined as previously thought.

Further complicating the concept of hierarchical organization is the recent demonstration that cancer cells fractions re-establish cellular equilibrium irrespective of the cell surface markers utilized to sort subpopulations [60••]. Gupta et al. [60••] showed that in multiple breast cancer cell lines, the cancer stem-like fraction, as well as the more differentiated basal and luminal cell fractions formed tumors with high efficiency when co-injected with irradiated carrier cells. In response to appropriate microenvironmental cues, sorted cell fractions do not remain static and inevitably give rise to other phenotypes. We have seen similar trends in our laboratory with sorted populations from pediatric medulloblastoma cell lines [61].

\section{In Search of New and Improved In Vivo Models}

As CSC research moves forward, we will continuously look for ways to improve existing models and optimize methods for putative CSC detection. Researchers are now working with more "humanized" xenograft models by coinjecting human cancer cells or sorted cancer cell populations with normal carrier cells [60••] or extracellular matrix proteins such as Matrigel [15, 18••, 62]. To date, these methods have been successful in not only enhancing the readout or frequency of cells with known tumorigenic 
capacity, but also the number of different phenotypes capable of transplanting disease. In vivo models that combine tumor cell populations and accessory proteins or support cells represent a step towards a more realistic view of the true complexities of the heterogeneous tumor microenvironment.

This review primarily focused on murine models of CSCs; however, recent studies have proposed other systems for the study of CSC populations. For example, Barbieri et al. [63] have isolated CSC-like cells from feline mammary carcinoma. Upon injection into NOD/SCID mice, these cells generate heterogeneous tumors that recapitulate the original phenotype [63]. Cocola et al. [64] have conducted similar experiments with canine mammary carcinoma. Eguiara et al. [65] have proposed using zebrafish xenograft models as an alternative to the highly expensive mouse experiments that require more maintenance and can last upwards of several months. In particular, zebrafish embryos were utilized as a functional assay for breast cancer stem-like cell identification [65]. Zebrafish are increasingly employed as useful pre-clinical models for therapeutic testing and high-throughput screening, as they can be bred in large numbers, are easy and inexpensive to maintain, are immunodeficient for up until 11 days post-fertilization and are, therefore, permissive to human cancer cells [66-68]. Using this model system, Eguiara et al. [65] found that breast cancer cell lines grown as tumorspheres formed masses and migrated to the tail at a higher frequency then cells grown as monolayers. While definitely not mainstream, the zebrafish model may provide a viable alternative for future large-scale studies that attempt to identify new therapeutic strategies specifically aimed at eradicating the CSC population.

\section{Conclusions}

The last 15 years have been an exciting time in cancer research. With the identification of CSC populations in a variety of cancers including leukemia [5, 6], breast [7], brain $[8,9]$, colon $[10,11]$, pancreatic [12] and ovarian cancers [1316], researchers are now focusing their efforts on finding new therapies that will specifically target and eradicate this cell population. Despite these intensive efforts, CSC theory has been riddled with controversy. The in vivo models used to define these populations have several caveats including differences in frequency or readout of CSCs, discrepancies in the cell surface markers that select for CSCs, and variation in the number and phenotype of cell populations that display tumorigenic capacity. Furthermore, the relationship between CSCs and highly invasive or metastatic cells is still underdeveloped with few studies to date directly comparing these properties [41, 42, 69-72]. In our laboratory, we have shown that medulloblastoma tumorspheres from cell lines exhibit downregulation of a cell motility transcription program in vitro [61]. It will be interesting to see whether highly malignant pediatric brain tumor cells in a "stem cell state" also display this same suppression of cell motility genes in vivo. An inverse correlation would suggest that drugs targeting cells in the migratory or invasive state will not abrogate the putative CSCs in a state of enhanced self-renewal. Furthermore, recent studies demonstrating interconversion between stem cell and more differentiated states raise more questions: Will one cell phenotype compensate for another following treatment, thereby negating the long-term benefit of cell-directed therapies? If CSCs are a "moving target", then how can we expect to tackle the daunting task of completely eradicating them? Our long-term goal is to identify novel therapeutic targets that will eliminate not only the cells responsible for tumor initiation and propagation but also the highly infiltrative cells that are the basis for recurrence.

Whether most or only a few cancers follow a CSC model remains an unanswered question. In vivo transplantation assays combined with more cell specific marking and fate mapping and advanced imaging technologies will be imperative for the future. Whether your system of choice is a "humanized" xenograft, a GEM or a zebrafish, we will continue to question whether these models can ever truly recapitulate the human tumor microenvironment? However, any cell population that displays the ability to initiate tumorigenesis, to maintain it, or to invade and/or metastasize in any model system should be carefully studied and dissected. As optimization of animal models continues, and our understanding of CSC theory evolves, our view of CSCs within a heterogeneous tumor environment will likely become even more complex.

Disclosure C. Aiken and T. Werbowetski-Ogilvie declares that they have no conflict of interest.

\section{References}

Papers of particular interest, published recently, have been highlighted as:

- Of importance

•- Of major importance

1. Rosen JM, Jordan CT (2009) The increasing complexity of the cancer stem cell paradigm. Science 324(5935):1670-1673

2. Visvader JE (2011) Cells of origin in cancer. Nature 469(7330): 314-322. doi:10.1038/nature09781

3. Magee JA, Piskounova E, Morrison SJ (2012) Cancer stem cells: impact, heterogeneity, and uncertainty. Cancer Cell 21(3): 283-296. doi:10.1016/j.ccr.2012.03.003

4. Dick JE (2008) Stem cell concepts renew cancer research. Blood 112(13):4793-4807. doi:10.1182/blood-2008-08-077941 
5. Bonnet D, Dick JE (1997) Human acute myeloid leukemia is organized as a hierarchy that originates from a primitive hematopoietic cell. Nat Med 3(7):730-737

6. Lapidot T, Sirard C, Vormoor J, Murdoch B, Hoang T, CaceresCortes J et al (1994) A cell initiating human acute myeloid leukaemia after transplantation into SCID mice. Nature 367(6464): 645-648. doi:10.1038/367645a0

7. Al-Hajj M, Wicha MS, Benito-Hernandez A, Morrison SJ, Clarke MF (2003) Prospective identification of tumorigenic breast cancer cells. Proc Natl Acad Sci USA 100(7):3983-3988

8. Singh SK, Hawkins C, Clarke ID, Squire JA, Bayani J, Takulchiro $\mathrm{H}$ et al (2004) Identification of human brain tumour initiating cells. Nature 432:396-401

9. Singh SK, Clarke ID, Terasaki M, Bonn VE, Hawkins C, Squire J et al (2003) Identification of a cancer stem cell in human brain tumors. Cancer Res 63(18):5821-5828

10. O'Brien CA, Pollett A, Gallinger S, Dick JE (2007) A human colon cancer cell capable of initiating tumour growth in immunodeficient mice. Nature 445(7123):106-110

11. Ricci-Vitiani L, Lombardi DG, Pilozzi E, Biffoni M, Todaro M, Peschle $\mathrm{C}$ et al (2007) Identification and expansion of human colon-cancer-initiating cells. Nature 445(7123):111-115

12. Li C, Heidt DG, Dalerba P, Burant CF, Zhang L, Adsay V et al (2007) Identification of pancreatic cancer stem cells. Cancer Res 67(3):1030-1037. doi:10.1158/0008-5472.CAN-06-2030

13. Alvero AB, Chen R, Fu HH, Montagna M, Schwartz PE, Rutherford $\mathrm{T}$ et al (2009) Molecular phenotyping of human ovarian cancer stem cells unravels the mechanisms for repair and chemoresistance. Cell Cycle 8(1):158-166

14. Curley MD, Therrien VA, Cummings CL, Sergent PA, Koulouris CR, Friel AM et al (2009) CD133 expression defines a tumor initiating cell population in primary human ovarian cancer. Stem Cells 27(12):2875-2883. doi:10.1002/stem.236

15. Stewart JM, Shaw PA, Gedye C, Bernardini MQ, Neel BG, Ailles LE (2011) Phenotypic heterogeneity and instability of human ovarian tumor-initiating cells. Proc Natl Acad Sci USA 108(16):6468-6473. doi:10.1073/pnas.1005529108

16. Zhang S, Balch C, Chan MW, Lai HC, Matei D, Schilder JM et al (2008) Identification and characterization of ovarian cancer-initiating cells from primary human tumors. Cancer Res 68(11): 4311-4320. doi:10.1158/0008-5472.CAN-08-0364

17. •• Kelly PN, Dakic A, Adams JM, Nutt SL, Strasser A (2007) Tumor growth need not be driven by rare cancer stem cells. Science 317(5836):337. This was the first study to demonstrate that putative cancer stem cell populations did not have to be rare. The authors showed that tumorigenic cells were more common in certain mouse models of lymphoma and AML. Transplantation with as few as 10 cells resulted in tumor development

18. •• Quintana E, Shackleton M, Sabel MS, Fullen DR, Johnson TM, Morrison SJ (2008) Efficient tumour formation by single human melanoma cells. Nature 456(7222):593-598. This study showed that the frequency or readout of tumorigenic cells can be significantly increased by using more highly immunocompromised mice. For melanoma, xenotransplantation assays in NOD/SCID $I L 2 R \gamma^{\text {null }}$ mice resulted in an average of 1 in 9 melanoma cells forming tumors. This study showed that modified in vivo assay conditions can dramatically change the CSC output

19. Wang JC, Doedens M, Dick JE (1997) Primitive human hematopoietic cells are enriched in cord blood compared with adult bone marrow or mobilized peripheral blood as measured by the quantitative in vivo SCID-repopulating cell assay. Blood 89(11):3919-3924

20. Porter EH, Berry RJ (1963) The efficient design of transplantable tumour assays. Br J Cancer 17:583-595

21. Kuperwasser C, Chavarria T, Wu M, Magrane G, Gray JW, Carey $\mathrm{L}$ et al (2004) Reconstruction of functionally normal and malignant human breast tissues in mice. Proc Natl Acad Sci USA 101(14):4966-4971. doi:10.1073/pnas.0401064101

22. Joyce JA (2005) Therapeutic targeting of the tumor microenvironment. Cancer Cell 7(6):513-520. doi:10.1016/j.ccr.2005.05. 024

23. Schatton T, Murphy GF, Frank NY, Yamaura K, Waaga-Gasser AM, Gasser $M$ et al (2008) Identification of cells initiating human melanomas. Nature 451(7176):345-349. doi:10.1038/nature06489

24. Kennedy JA, Barabe F, Poeppl AG, Wang JC, Dick JE (2007) Comment on "Tumor growth need not be driven by rare cancer stem cells". Science 318(5857):1722; author reply doi: 10.1126/science. 1149590

25. Ishikawa F, Yoshida S, Saito Y, Hijikata A, Kitamura H, Tanaka $S$ et al (2007) Chemotherapy-resistant human AML stem cells home to and engraft within the bone-marrow endosteal region. Nat Biotechnol 25(11):1315-1321. doi:10.1038/nbt1350

26. - Eppert K, Takenaka K, Lechman ER, Waldron L, Nilsson B, van Galen $\mathrm{P}$ et al (2011) Stem cell gene expression programs influence clinical outcome in human leukemia. Nat Med 17(9):1086-1093. doi:10.1038/nm.2415. This study showed linked the gene expression signatures in sorted fractions of $A M L$ with patient survival. The authors evaluated the leukemia initiating capacity of CD34+/CD38-, CD34+/CD38+ and CD34fractions in AML from 16 patients and showed that leukemogenic activity is not restricted to the CD34+/CD38- fraction

27. Ishizawa K, Rasheed ZA, Karisch R, Wang Q, Kowalski J, Susky $\mathrm{E}$ et al (2010) Tumor-initiating cells are rare in many human tumors. Cell Stem Cell 7(3):279-282. doi:10.1016/j.stem.2010. 08.009

28. Buchstaller J, McKeever PE, Morrison SJ (2011) Tumorigenic cells are common in mouse MPNSTs but their frequency depends upon tumor genotype and assay conditions. Cancer Cell 21(2): 240-252. doi:10.1016/j.ccr.2011.12.027

29. Hochedlinger K, Blelloch R, Brennan C, Yamada Y, Kim M, Chin L et al (2004) Reprogramming of a melanoma genome by nuclear transplantation. Genes Dev 18(15):1875-1885

30. Utikal J, Maherali N, Kulalert W, Hochedlinger K (2009) Sox2 is dispensable for the reprogramming of melanocytes and melanoma cells into induced pluripotent stem cells. J Cell Sci 122(Pt 19):3502-3510

31. Williams RT, den Besten W, Sherr CJ (2007) Cytokine-dependent imatinib resistance in mouse BCR-ABL+, Arf-null lymphoblastic leukemia. Genes Dev 21(18):2283-2287. doi:10.1101/ gad. 1588607

32. Held MA, Curley DP, Dankort D, McMahon M, Muthusamy V, Bosenberg MW (2010) Characterization of melanoma cells capable of propagating tumors from a single cell. Cancer Res 70(1):388-397. doi:10.1158/0008-5472.CAN-09-2153

33. Vaillant F, Asselin-Labat ML, Shackleton M, Forrest NC, Lindeman GJ, Visvader JE (2008) The mammary progenitor marker CD61/beta3 integrin identifies cancer stem cells in mouse models of mammary tumorigenesis. Cancer Res 68(19):7711-7717. doi: 10.1158/0008-5472.CAN-08-1949

34. Tamase A, Muraguchi T, Naka K, Tanaka S, Kinoshita M, Hoshii $\mathrm{T}$ et al (2009) Identification of tumor-initiating cells in a highly aggressive brain tumor using promoter activity of nucleostemin. Proc Natl Acad Sci USA 106(40):17163-17168. doi:10.1073/ pnas.0905016106

35. Marumoto T, Tashiro A, Friedmann-Morvinski D, Scadeng M, Soda Y, Gage FH et al (2009) Development of a novel mouse glioma model using lentiviral vectors. Nat Med 15(1):110-116. doi: $10.1038 / \mathrm{nm} .1863$

36. Cho RW, Wang X, Diehn M, Shedden K, Chen GY, Sherlock G et al (2008) Isolation and molecular characterization of cancer stem cells in MMTV-Wnt-1 murine breast tumors. Stem Cells 26(2):364-371. doi:10.1634/stemcells.2007-0440 
37. Zhang M, Behbod F, Atkinson RL, Landis MD, Kittrell F, Edwards D et al (2008) Identification of tumor-initiating cells in a p53-null mouse model of breast cancer. Cancer Res 68(12):4674-4682. doi:10.1158/0008-5472.CAN-07-6353

38. Ma J, Lanza DG, Guest I, Uk-Lim C, Glinskii A, Glinsky G et al (2012) Characterization of mammary cancer stem cells in the MMTV-PyMT mouse model. Tumour Biol 33(6):1983-1996. doi:10.1007/s13277-012-0458-4

39. Grange C, Lanzardo S, Cavallo F, Camussi G, Bussolati B (2008) Sca-1 identifies the tumor-initiating cells in mammary tumors of BALB-neuT transgenic mice. Neoplasia 10(12):1433-1443

40. Joo KM, Kim SY, Jin X, Song SY, Kong DS, Lee JI et al (2008) Clinical and biological implications of CD133-positive and CD133-negative cells in glioblastomas. Lab Invest 88(8):808-815

41. Chen R, Nishimura MC, Bumbaca SM, Kharbanda S, Forrest WF, Kasman IM et al (2010) A hierarchy of self-renewing tumorinitiating cell types in glioblastoma. Cancer Cell 17(4):362-375. doi:10.1016/j.ccr.2009.12.049

42. Shmelkov SV, Butler JM, Hooper AT, Hormigo A, Kushner J, Milde $\mathrm{T}$ et al (2008) CD133 expression is not restricted to stem cells, and both CD133+ and CD133- metastatic colon cancer cells initiate tumors. J Clin Invest 118(6):2111-2120

43. Ogden AT, Waziri AE, Lochhead RA, Fusco D, Lopez K, Ellis JA et al (2008) Identification of A2B5+CD133 - tumor-initiating cells in adult human gliomas. Neurosurgery 62(2):505-514 discussion 514-515

44. Wang J, Sakariassen PO, Tsinkalovsky O, Immervoll H, Boe SO, Svendsen A et al (2008) CD133 negative glioma cells form tumors in nude rats and give rise to CD133 positive cells. Int J Cancer 122(4):761-768

45. Wu Y, Wu PY (2009) CD133 as a marker for cancer stem cells: progresses and concerns. Stem Cells Dev 18(8):1127-1134

46. Bidlingmaier S, Zhu X, Liu B (2008) The utility and limitations of glycosylated human CD133 epitopes in defining cancer stem cells. J Mol Med (Berl) 86(9):1025-1032

47. Lehnus KS, Donovan LK, Huang X, Zhao N, Warr TJ, Pilkington GJ et al (2013) CD133 glycosylation is enhanced by hypoxia in cultured glioma stem cells. Int J Oncol 42(3):1011-1017. doi: 10.3892/ijo.2013.1787

48. Blazek ER, Foutch JL, Maki G (2007) Daoy medulloblastoma cells that express CD133 are radioresistant relative to CD133cells, and the CD133+ sector is enlarged by hypoxia. Int J Radiat Oncol Biol Phys 67(1):1-5

49. Platet N, Liu SY, Atifi ME, Oliver L, Vallette FM, Berger F et al (2007) Influence of oxygen tension on CD133 phenotype in human glioma cell cultures. Cancer Lett 258(2):286-290

50. Read TA, Fogarty MP, Markant SL, McLendon RE, Wei Z, Ellison DW et al (2009) Identification of CD15 as a marker for tumor-propagating cells in a mouse model of medulloblastoma. Cancer Cell 15(2):135-147. doi:10.1016/j.ccr.2008.12.016

51. Ward RJ, Lee L, Graham K, Satkunendran T, Yoshikawa K, Ling E et al (2009) Multipotent CD15+ cancer stem cells in patched1-deficient mouse medulloblastoma. Cancer Res 69(11):46824690

52. Schuller U, Heine VM, Mao J, Kho AT, Dillon AK, Han YG et al (2008) Acquisition of granule neuron precursor identity is a critical determinant of progenitor cell competence to form Shhinduced medulloblastoma. Cancer Cell 14(2):123-134. doi:10. 1016/j.ccr.2008.07.005

53. Kawauchi D, Robinson G, Uziel T, Gibson P, Rehg J, Gao C et al (2012) A mouse model of the most aggressive subgroup of human medulloblastoma. Cancer Cell 21(2):168-180. doi:10.1016/j.ccr. 2011.12.023

54. Persson AI, Petritsch C, Swartling FJ, Itsara M, Sim FJ, Auvergne $\mathrm{R}$ et al (2010) Non-stem cell origin for oligodendroglioma. Cancer Cell 18(6):669-682. doi:10.1016/j.ccr.2010.10.033
55. Barrett LE, Granot Z, Coker C, Iavarone A, Hambardzumyan D, Holland EC et al (2012) Self-renewal does not predict tumor growth potential in mouse models of high-grade glioma. Cancer Cell 21(1):11-24. doi:10.1016/j.ccr.2011.11.025

56. Chen J, Li Y, Yu TS, McKay RM, Burns DK, Kernie SG et al (2012) A restricted cell population propagates glioblastoma growth after chemotherapy. Nature 488(7412):522-526. doi: 10.1038/nature 11287

57. • Taussig DC, Miraki-Moud F, Anjos-Afonso F, Pearce DJ, Allen K, Ridler C et al (2008) Anti-CD38 antibody-mediated clearance of human repopulating cells masks the heterogeneity of leukemia-initiating cells. Blood 112(3):568-575. doi: 10.1182/blood-2007-10-118331. This study demonstrated that anti-CD38 antibodies can have a profound inhibitory effect on the engraftment of AML cells. Overcoming the inhibitory effect led to the demonstration that for some AML samples, the leukemic initiating capacity is maintained in the CD34+/CD38+ fraction. This suggested that there is greater variation in the leukemic initiating phenotypes then once previously thought

58. Taussig DC, Vargaftig J, Miraki-Moud F, Griessinger E, Sharrock K, Luke T et al (2010) Leukemia-initiating cells from some acute myeloid leukemia patients with mutated nucleophosmin reside in the CD34(-) fraction. Blood 115(10):1976-1984. doi: 10.1182/blood-2009-02-206565

59. Sarry JE, Murphy K, Perry R, Sanchez PV, Secreto A, Keefer Cet al (2011) Human acute myelogenous leukemia stem cells are rare and heterogeneous when assayed in NOD/SCID/IL2R $\gamma$ c-deficient mice. J Clin Invest 121(1):384-395. doi:10.1172/JCI41495

60. • Gupta PB, Fillmore CM, Jiang G, Shapira SD, Tao K, Kuperwasser C et al (2011) Stochastic state transitions give rise to phenotypic equilibrium in populations of cancer cells. Cell 146(4):633-644. doi:10.1016/j.cell.2011.07.026. Using mathematical modeling, this study showed that interconversion of cancer cells between various differentiation states enables reestablishment of cellular equilibrium irrespective of the cell surface markers utilized to sort subpopulations. The authors used multiple breast cancer cell lines to demonstrate that sorted cell fractions are not static and will inevitably give rise to other phenotypes in response to appropriate microenvironmental cues

61. Morrison LC, McClelland R, Aiken C, Bridges M, Liang L, Wang X et al (2013) Deconstruction of medulloblastoma cellular heterogeneity reveals differences between the most highly invasive and self-renewing phenotypes. Neoplasia (in press)

62. Fridman R, Benton G, Aranoutova I, Kleinman HK, Bonfil RD (2012) Increased initiation and growth of tumor cell lines, cancer stem cells and biopsy material in mice using basement membrane matrix protein (Cultrex or Matrigel) co-injection. Nat Protoc 7(6):1138-1144. doi:10.1038/nprot.2012.053

63. Barbieri F, Wurth R, Ratto A, Campanella C, Vito G, Thellung S et al (2012) Isolation of stem-like cells from spontaneous feline mammary carcinoma: phenotypic characterization and tumorigenic potential. Exp Cell Res 318(7):847-860. doi:10.1016/j. yexcr.2012.02.008

64. Cocola C, Anastasi P, Astigiano S, Piscitelli E, Pelucchi P, Vilardo L et al (2009) Isolation of canine mammary cells with stem cell properties and tumour-initiating potential. Reprod Domest Anim 44(Suppl 2):214-217. doi:10.1111/j.1439-0531.2009. 01413.x

65. Eguiara A, Holgado O, Beloqui I, Abalde L, Sanchez Y, Callol C et al (2011) Xenografts in zebrafish embryos as a rapid functional assay for breast cancer stem-like cell identification. Cell Cycle 10(21):3751-3757. doi:10.4161/cc.10.21.17921

66. Zon LI, Peterson RT (2005) In vivo drug discovery in the zebrafish. Nat Rev Drug Discov 4(1):35-44. doi:10.1038/nrd1606

67. Lee LM, Seftor EA, Bonde G, Cornell RA, Hendrix MJ (2005) The fate of human malignant melanoma cells transplanted into 
zebrafish embryos: assessment of migration and cell division in the absence of tumor formation. Dev Dyn 233(4):1560-1570. doi: 10.1002/dvdy.20471

68. Haldi M, Ton C, Seng WL, McGrath P (2006) Human melanoma cells transplanted into zebrafish proliferate, migrate, produce melanin, form masses and stimulate angiogenesis in zebrafish. Angiogenesis 9(3):139-151. doi:10.1007/s10456-006-9040-2

69. Mani SA, Guo W, Liao MJ, Eaton EN, Ayyanan A, Zhou AY et al (2008) The epithelial-mesenchymal transition generates cells with properties of stem cells. Cell 133(4):704-715

70. Pang R, Law WL, Chu AC, Poon JT, Lam CS, Chow AK et al (2010) A subpopulation of CD26+ cancer stem cells with metastatic capacity in human colorectal cancer. Cell Stem Cell 6(6):603-615. doi:10.1016/j.stem.2010.04.001

71. Charafe-Jauffret E, Ginestier C, Iovino F, Wicinski J, Cervera N, Finetti $\mathrm{P}$ et al (2009) Breast cancer cell lines contain functional cancer stem cells with metastatic capacity and a distinct molecular signature. Cancer Res 69(4):1302-1313. doi:10.1158/00085472.CAN-08-2741

72. Molina JR, Hayashi Y, Stephens C, Georgescu MM (2010) Invasive glioblastoma cells acquire stemness and increased Akt activation. Neoplasia 12(6):453-463 